2. P. C. Brooks et al., Cell 85, 683 (1996); H. Sato et al., Nature 370, 61 (1994); C. B. Basbaum and Z. Werb, Curr. Opin. Cell Biol. 8, 731 (1996).

3. R. E. Burgeson et al., Matrix Biol. 14, 209 (1994); G. W. Laurie, C. P. Leblond, G. R. Martin, J. Cell Biol. 95, 340 (1982)

4. S. E. Baker et al., J. Cell Sci. 109, 2509 (1996).

5. K. Miyazaki, Y. Kikkawa, A. Nakamura, H. Yasumitsu, M. Umeda, Proc. Natl. Acad. Sci. U.S.A. 90, 11767 (1993).

6. P. Basset et al., Nature 348, 699 (1990); C. Monteagudo, M. J. Merino, J. San-Juan, L. A. Liotta, W. G. Stetler-Stevenson, Am. J. Pathol. 136, 585 (1990)

7. A. J. Pelletier, T. Kunicki, V. Quaranta, J. Biol. Chem. 271, 1364 (1996)

8. H. D. Soule et al., Cancer Res. 50, 6075 (1990).

9. G. Giannelli and V. Quaranta, unpublished data

10. X. Wang, X. Fu, P. D. Brown, M. J. Crimmin, R. M. Hoffman, Cancer Res. 54, 4726 (1994).

11. M. Hormia et al., J. Invest. Dermatol. 105, 557 (1995)

12. G. Plopper et al., J. Cell Sci. 109, 1965 (1996).

13. A. L. Calof, M. R. Campanero, J. J. O'Rear, P. D. Yurchenco, A. D. Lander, Neuron 13, 117 (1994); S. Stefansson and D. A. Lawrence, Nature 383, 441 (1996).

14. M. Aumailley, M. Gerl, A. Sonnenberg, R. Deutzmann, R. Timpl, FEBS Lett. 262, 82 (1990); P. I. Karecla, R. Timpl, F. M. Watt, Cell Adhes. Commun. 2, 309 (1994).

15. D. A. Lauffenburger and A. F. Horwitz, Cell 84, 359 (1996)

16. Y. Itoh, S. Binner, H. Nagase, Biochem. J. 308, 645 (1995).

17. S. M. Wilhelm et al., J. Biol. Chem. 264, 17213 (1989)

18. G. Giannelli et al., Lab. Invest. 74, 1091 (1996).

19. M. Langhofer, S. B. Hopkinson, J. C. R. Jones, J. Cell Sci. 105, 753 (1993)

20. C. A. Burdsal, M. C. Alliegro, D. R. McClay, Dev. Biol. 144, 327 (1991).

21. R. Fridman et al., Biochem. J. 289, 411 (1993).

22. For migration assays (7), transwell filters were coated on the underside with $\mathrm{Ln}-5(1 \mu \mathrm{g} / \mathrm{ml})$, Coll IV (10 $\mu \mathrm{g} / \mathrm{ml}$, Gibco-BRL), Ln-1 (20 $\mu \mathrm{g} / \mathrm{ml}$; Collaborative, Becton-Dickinson, Bedford, MA), or Fn $(20 \mu \mathrm{g} / \mathrm{ml}$, Gibco-BRL). Filters were washed and cells were plated in the upper transwell chamber. After 16 hours at $37^{\circ} \mathrm{C}$, filters were fixed and stained, and cells that migrated to the underside were quantified by counting four microscopic fields from duplicate filters. Results are the mean number of cells counted in each field \pm SD. In some experiments (Fig. $3 \mathrm{C}$ ), after blocking, filters were incubated with indicated mAbs $(100 \mu \mathrm{g})(12)$. In Fig. 3, D to F, filters precoated with Ln-1, Coll IV, or Fn were recoated with MMP2cleaved Ln-5 followed by addition of BB94 and mAbs.

23. Rat Ln-5 was purified from the spent media of $804 \mathrm{G}$ cells (11). As judged by SDS-polyacrylamide ge electrophoresis (PAGE), some Ln-5 purified preparations contain a small amount of $\gamma 2$ that migrates as a band at $135 \mathrm{kD}$. Ln-5 (100 ng) was incubated for 2 to 24 hours at $37^{\circ} \mathrm{C}$ with indicated concentrations of recombinant activated MMP2 (16), inactive proMMP2, recombinant active MMP9 (17), or highly purified plasmin (Enzyme Research Laboratory, South Bend, IN), and then analyzed by protein immunoblotting (18). The same results were obtained with semipurified Ln-5 (9). We verified activation and purity of MMP2 and MMP9 by zymography (18). We determined that plasmin cleaved fibrinogen with the expected pattern even at concentrations 1000 times the Ln-5 concentration used. Polyclonal antiserum 2163 to the $\gamma 2$ chain was from rabbits injected with $\gamma 2^{\prime}$ protein, purified by excision from SDS-PAGE gels (19). Tissues were pulverized, resuspended in $0.05 \mathrm{M}$ tris- $\mathrm{HCl}$ (pH 7.4), $0.01 \mathrm{M}$ EDTA, BB94 (50 ng/ml), and phenyl methylsulfonyl fluoride $(1 \mathrm{mg} / \mathrm{ml})$, and centrifuged at $17,200 \mathrm{~g}$ for $30 \mathrm{~min}$ at $4^{\circ} \mathrm{C}$; the pellet was resuspended in sample buffer, sonicated, and analyzed by protein immunoblot. Cleaved Ln-5 was prepared as described (18), and the $\mathrm{NH}_{2}$-terminal se-

quence from the $80-\mathrm{kD}$ polypeptide was obtained by automated Edman degradation. Rat $\gamma 2 \mathrm{cDNA}$ was cloned by homology screening and sequenced from an 804G cell $\lambda$ gt11 cDNA library (Clontech, Palo Alto, CA).

24. M. P. Marinkovich, G. P. Lunstrum, R. E. Burgeson, J. Biol. Chem. 267, 17900 (1992)

25. C. Pyke et al., Cancer Res. 55, 4132 (1995)

26. MCF-10 cells were plated for 2 hours at $37^{\circ} \mathrm{C}$ on glass cover slips coated with Ln-5 (19), washed, fixed, and photographed with an Axiovert 135 microscope (Zeiss).

27. The mAbs TR1, CM6, and MIG1 $(20 \mu \mathrm{g} / \mathrm{ml})$ were adsorbed for 1 hour at room temperature on 96-well plates (Sarstedt, Sparks, NV). After blocking, intact or cleaved Ln- 5 was captured in wells for 2 hours, and $8 \times 10^{4}$ cells per well were added in Dulbecco's modified Eagle's medium with $1 \%$ bovine serum albumin. Plates were incubated at $37^{\circ} \mathrm{C}$ in a humidified incubator under $10 \% \mathrm{CO}_{2}$ for $30 \mathrm{~min}$, filled with phosphate-buffered saline (PBS), inverted, and gently shaken in a tank of PBS for 15 min. Excess

\title{
Niemann-Pick C1 Disease Gene: Homology to Mediators of Cholesterol Homeostasis
}

\section{Eugene D. Carstea, ${ }^{*}$ Jill A. Morris, ${ }^{*}$ Katherine G. Coleman, Stacie K. Loftus, Dana Zhang, Christiano Cummings, Jessie Gu, Melissa A. Rosenfeld, William J. Pavan, David B. Krizman, James Nagle, Mihail H. Polymeropoulos, Stephen L. Sturley, Yiannis A. loannou, Maureen E. Higgins, Marcella Comly, Adele Cooney, Anthony Brown, Christine R. Kaneski, E. Joan Blanchette-Mackie,} Nancy K. Dwyer, Edward B. Neufeld, Ta-Yuan Chang, Laura Liscum, Jerome F. Strauss III, Kousaku Ohno, Marsha Zeigler, Rivka Carmi, Jacob Sokol, David Markie, Raymond R. O'Neill, O. P. van Diggelen, Milan Elleder, Marc C. Patterson, Roscoe O. Brady, Marie T. Vanier, Peter G. Pentchev, $\dagger$ Danilo A. Tagle

Niemann-Pick type C (NP-C) disease, a fatal neurovisceral disorder, is characterized by lysosomal accumulation of low density lipoprotein (LDL)-derived cholesterol. By positional cloning methods, a gene (NPC1) with insertion, deletion, and missense mutations has been identified in NP-C patients. Transfection of NP-C fibroblasts with wild-type NPC1 cDNA resulted in correction of their excessive lysosomal storage of LDL cholesterol, thereby defining the critical role of NPC1 in regulation of intracellular cholesterol trafficking. The 1278-amino acid NPC1 protein has sequence similarity to the morphogen receptor PATCHED and the putative sterol-sensing regions of SREBP cleavage-activating protein (SCAP) and 3-hydroxy-3-methyl-glutaryl coenzyme A (HMG-CoA) reductase.

Genetic disorders have helped to define critical steps of cellular metabolism. For example, elucidation of the biochemical and genetic defects underlying familial hypercholesterolemia (FH) laid the cornerstone for the discovery of the LDL-receptor pathway of cellular cholesterol metabolism (1). Similarly, the role of lysosomes and cholesteryl ester (CE) hydrolase in the processing of the CE core of $\mathrm{LDL}$ was revealed by Wolman's syndrome, a lysosomal CE storage disease (2).
Niemann-Pick type C (NP-C) disease is an inherited lipid storage disorder that affects the viscera and central nervous system (3). It occurs at low frequency (affecting one in $10^{6}$ individuals) and is inherited in an autosomal recessive manner. Both linkage and complementation analyses have shown that at least two separate genes, NPC1 (major locus) and NPC2, induce identical clinical and biochemical phenotypes (4). Cells from NP-C patients are defective in the release 
of cholesterol from lysosomes (5). This lysosomal sequestration of LDL-derived cholesterol results in cholesterol processing errors, including delayed down-regulation of both LDL uptake and de novo sterol synthesis, as well as repressed cholesterol esterification. The NP-C phenotype suggests that trafficking of lysosomal cholesterol to other cellular membranes is a protein-mediated process.

The NPC interval, previously assigned to pericentromeric chromosome 18 (6), was narrowed to a 1-centimorgan region of $18 \mathrm{q} 11$ defined by markers D18S44 and D18S1388 $(7,8)$. A minimal set of overlapping yeast artificial chromosomes (YACs) and bacterial artificial chromosomes (BACs) was assembled (Fig. 1) (7). YACs that define the region were introduced into cultured NP-C cells through spheroplast fusion. YAC 911_D_5 exclusively conferred a normal phenotype to mutant cells, establishing the presence of the NPCl gene on this YAC (9) and reducing the NPC interval to markers D18S1382 and D18S1388, an estimated distance of $300 \mathrm{~kb}$. BACs assembled across the narrowed NP-C interval were subcloned into exon-trapping vectors (10). Among the trapped exons that mapped to YAC 911_D_5 and its associated BACs

E. D. Carstea, J. A Morris, K. G. Coleman, D. Zhang, C Cummings, J. Nagle, M. Comly, A. Cooney, A. Brown C. R. Kaneski, R. R. O'Neill, R. O. Brady, P. G. Pentchev, National Institute of Neurological Disorders and Stroke, National Institutes of Health (NIH), Bethesda, MD 20892 , USA.

S. K. Loftus, J. Gu, M. A. Rosenfeld, W. J. Pavan, M. H. Polymeropoulos, D. A. Tagle, National Human Genome Research Institute, NIH, Bethesda, MD 20892, USA. D. B. Krizman, National Cancer Institute, NIH, Bethesda, MD 20892, USA.

S. L. Sturley, Columbia University College of Physicians and Surgeons, New York, NY 10032, USA.

Y. A. Ioannou and M. E. Higgins, Mount Sinai School of Medicine, New York, NY 10029, USA.

E. J. Blanchette-Mackie, N. K. Dwyer, E. B. Neufeld, National Institute of Diabetes and Digestive and Kidney Diseases, NIH, Bethesda, MD 20892, USA.

T.-Y. Chang, Dartmouth Medical School, Hanover, NH 03755, USA.

L. Liscum, Tufts University School of Medicine, Boston, MA 02111, USA

J. F. Strauss III, University of Pennsylvania, Philadelphia, PA 19104, USA

K. Ohno, Tottori University Faculty of Medicine, Yanago, Japan.

M. Zeigler, Hadassah University Hospital, Jerusalem, Israel.

R. Carmi, Ben-Gurion University of the Negev, BeerSheva, Israel.

J. Sokol, Hillel Yaffe Medical Center, Hadera, Israel.

D. Markie, Dunedin School of Medicine, Dunedin, New Zealand.

O. P. van Diggelen, Erasmus University, Rotterdam, The Netherlands.

M. Elleder, Faculty of Medicine and University Hospital, Prague, Czech Republic.

M. C. Patterson, Mayo Clinic, Rochester, MN 55905, USA.

M. T. Vanier', INSERM U 189, Oullins, France.

*These authors contributed equally to this study. $\dagger$ To whom correspondence should be addressed. E-mail: pentchev@codon.nih.gov

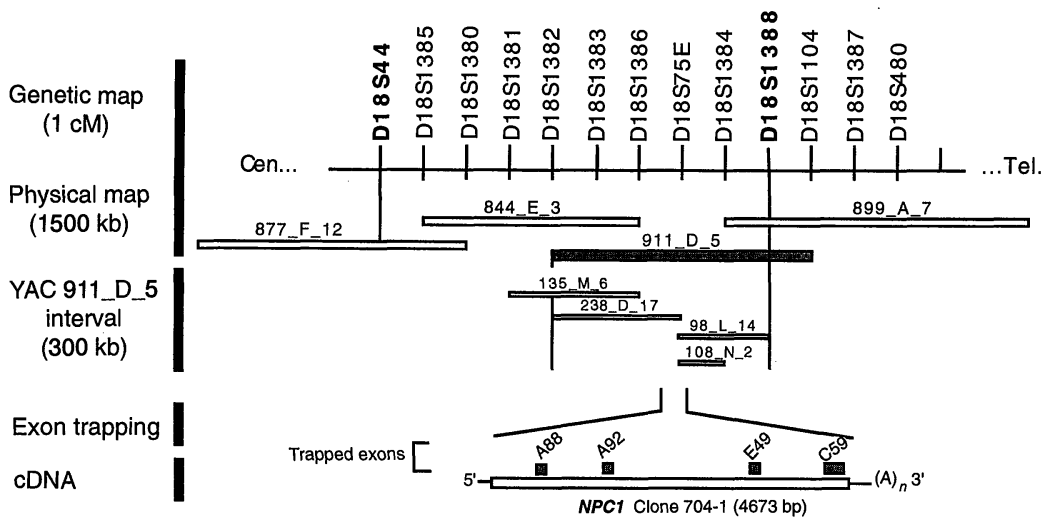

Fig. 1. Positional cloning of the NPC1 gene. The 1-cM genetic interval, covering a physical distance of $\sim 1500 \mathrm{~kb}$, is defined by microsatellite markers D18S44 and D18S1388. It is represented schematically by equally spaced loci and is not drawn to scale. Complementation with YAC 911. D_5 (hatched) refined the interval to a region between D18S1382 and D18S1388. BACs were assembled across the NP-C interval and used to generate genomic subclones for exon trapping. Of the resultant trapped inserts, four of the verified exons-A88, A92, E49, and C59-mapped to NPC1. The 4673-bp cDNA is represented by an ORF of $3834 \mathrm{bp}$ and a 713-bp $3^{\prime}$ UTR.

(Fig. 1), the 3' exon C59 showed identity to an expressed sequence tag (EST) H11600 (GenBank) and the corresponding cluster of 14 ESTs (WI-14881) identified by UNIGENE (11). Northern blot analysis of a multi-tissue RNA panel (Clontech) with EST clone H11600 as probe identified a transcript of $\sim 4.9 \mathrm{~kb}$ (7). To extend this clone $5^{\prime}$, we designed antisense primers from clone $\mathrm{H} 11600$ and used them to amplify sequences from adapter-ligated cDNA libraries (12) Through successive extensions, the sequence of the entire open reading frame (ORF) was identified. Primers corresponding to the $5^{\prime}$ most and $3^{\prime}$ most sequences were then used to amplify a single 4673base pair (bp) clone, 704-1, containing the entire ORF. We now refer to clone 704-1 as NPC1. The authenticity of this clone was verified by three additional trapped internal exons that mapped to the NPC1 ORF (Fig. 1).

The NPC1 cDNA sequence predicts a protein of 1278 amino acids with an estimated molecular mass of $142 \mathrm{kD}$ (Fig. 2A)
(13). The $\mathrm{NH}_{2}$-terminus contains 13 hydrophobic amino acids typical of signal peptides that target proteins to the endoplasmic reticulum (ER). Analysis of regions of hydrophobicity and structural motif comparisons predict an integral membrane protein with as many as 13 to 16 possible transmembrane (TM) regions. The COOH-terminus of NPC1 contains a di-leucine motif (LLNF) that serves as a lysosomal targeting sequence for Limp II, a lysosomal resident protein with multiple TM domains (14). This motif also mediates endocytosis (15). Database sequence comparisons revealed extensive resemblance (\% identity/\% similarity) to uncharacterized NP-C orthologs in mouse (16) $(85 / 93)$, the yeast Saccharomyces cerevisiae (34/57), and the nematode Caenorhabditis elegans (30/55). A region between residues 55 to 165 , which is free of TM domains, is highly conserved, suggesting that it has functional importance. Within this sequence lies a leucine zipper motif (residues 73 to 94 ) that may mediate protein multimerization as it does for certain

Table 1. Mutations of NPC1 gene in Niemann-Pick type $\mathrm{C}$ patients from different families. nt, nucleotide; aa, amino acid; Cmpd heteroz., compound heterozygote; Homoz., homozygote.

\begin{tabular}{|c|c|c|c|c|}
\hline Patient & $\begin{array}{l}\text { mRNA sequence } \\
\text { change }\end{array}$ & $\begin{array}{l}\text { Predicted protein } \\
\text { alteration }\end{array}$ & $\begin{array}{l}\text { Transmembrane } \\
\text { region affected }\end{array}$ & Genotype \\
\hline NZ 145 & nt 599/Del/6 bp (AGGCAC) & Del aa 200-201 (Gln, Ala) & - & Cmpd heteroz \\
\hline 93.47 & nt $1875 / \mathrm{Del} / 73 \mathrm{bp}$ & Frameshift/aa & - & Cmpd heteroz. \\
\hline 92.31 & nt $2783(A \rightarrow C)$ & aа $928 / G \mid n \rightarrow$ Pro & - & Cmpd heteroz. \\
\hline 87.15 & nt $3107(\mathrm{C} \rightarrow \mathrm{T})$ & aa $1036 /$ Thr $\rightarrow$ Met & 10 & Homoz. \\
\hline 94.17 & nt $3107(\mathrm{C} \rightarrow \mathrm{T})$ & aa $1036 /$ Thr $\rightarrow$ Met & 10 & Cmpd heteroz. \\
\hline \multirow[t]{2}{*}{94.41} & nt $3467(A \rightarrow G)$ & aa $1156 / \mathrm{Asn}^{*} \rightarrow$ Ser & 14 & Cmpd heteroz. \\
\hline & nt $3557(A \rightarrow G)$ & aa $1186 / \mathrm{Arg}^{*} \rightarrow \mathrm{His}$ & - & - \\
\hline ENZ146 & nt $3467(A \rightarrow G)$ & aa $1156 /$ Asn $^{*} \rightarrow$ Ser & 14 & Cmpd heteroz. \\
\hline 91.78 & nt $3499(T \rightarrow C)$ & aa $1167 /$ Phe $\rightarrow$ Leu & - & Cmpd heteroz. \\
\hline ENZ144 & nit 3613/Ins/4 bp (ACTT) & Frameshift/aa $1205 \rightarrow$ stop & $15-16$ & Cmpd heteroz. \\
\hline
\end{tabular}

${ }^{*}$ Conserved in human, mouse, C. elegans, and S. cerevisae orthologs. 
transcription factors (17). Residue 506 is a putative tyrosine phosphorylation site (18). Fourteen putative glycosylation sites are conserved between the human and mouse proteins (Fig. 2A).

The human NPC1 protein exhibits extensive homology with the TM regions of PATCHED, a morphogen receptor in Dro- sophila and the defective protein in basal cell nevus syndrome (19). Furthermore, across amino acids 615 to 797 , a region containing five predicted TM domains, NPC1 shows homology with sterol regulatory element binding protein (SREBP) cleavage-activating protein, SCAP (20), a modulator of cholesterol-regulated tran-

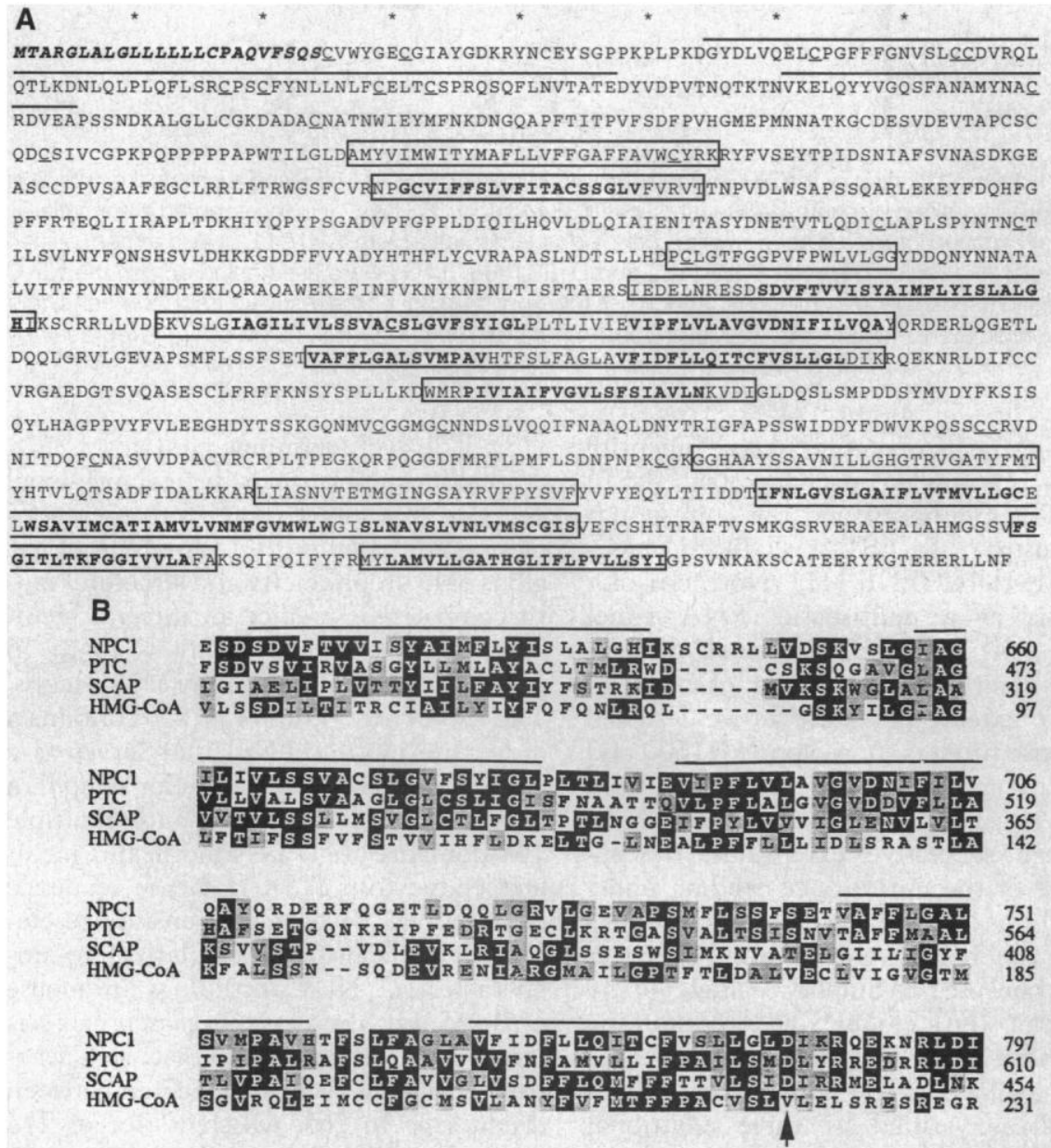

Fig. 2. (A) Predicted amino acid sequence of NPC1. The sequence (cDNA GenBank accession number AF002020) begins with the first methionine. The $\mathrm{NH}_{2}$-terminal sequence, in bold italics, designates the predicted signal peptide (13). Overlined sequences represent a domain that is conserved in mouse (16), C. elegans (GenBank accession number U53340), and S. cerevisiae (GenBank accession number U33335) orthologs. Conserved cysteines are underlined. Boxed sequences contain one or more of the 16 predicted TM domains, and the bold sequences therein are those that overlap with the 12 putative TM segments of human PATCHED. Several of the boxed sequences contain two (residues 652 to 709 744 to 788 ) or three (residues 1099 to 1164) predicted TM domains. The same TM prediction program and parameters were applied in human and mouse (16) sequences. Three marginally predicted TM domains in human (at residues 532 to 549,1014 to 1040, and 1060 to 1085) were identified in addition to the remaining 13 conserved between human and mouse. Potential $\mathrm{N}$-glycosylation sites conserved between human and mouse (16) are found at positions 70, 122, 185, 222, 314, 459, 478, 524, 557, 598 916, 961, and 968. (B) Amino acid sequence homology of NPC1-related proteins. Partial sequences of the sterol-sensing domain are from human NPC1, human PATCHED (PTC; GenBank accession number U59464), human HMG-CoA reductase (HMG-CoA; GenBank accession number M11058), and SCAP from Chinese hamster (SCAP; GenBank accession number U67060). Sequences were aligned with CLUSTAL and shaded with GCG PRETTY software. Residues with greater than $35 \%$ identity and similarity are shaded in black or gray, respectively. Regions of overlap in the predicted TM domains of NPC1 and PATCHED are overlined. Arrow indicates the D443N mutation of SCAP that results in sterol insensitivity (20). Dashes represent break in actual amino acid sequence of respective proteins to allow sequence alignment with NPC1. Abbreviations for the amino acid residues are as follows: A, Ala; C, Cys; D, Asp; E, Glu; F, Phe; G, Gly; H, His; I, Leu; M, Met; N, Asn; P, Pro; Q, Gln; R, Arg; S, Ser; T, Thr; V, Val; and W, Trp. scription factor activation, and with 3 hydroxy-3-methyl-glutaryl coenzyme A (HMG-CoA) reductase (21), the regulatory enzyme of de novo cholesterol biosynthesis (Fig. 2B). This region of SCAP and HMGCoA reductase is thought to contain sterolsensing domains (20). The degree of resemblance (\% identity/\% similarity) of this region of human NPC1 with the comparable region in human PATCHED, hamster SCAP, and human HMG-CoA reductase is $35 / 63,29 / 59$, and $24 / 62$, respectively.

Analysis of single-strand conformational polymorphisms (SSCPs) documented the presence of mutations in the NPC1 gene in NP-C patients (22). We identified eight distinct mutations in nine unrelated NP-C families (Table 1). One mutation was a 4-bp insertion that resulted in a frameshift at codon 1205, resulting in a premature termination. There were two multiple nucleotide deletions, including a 73-bp deletion resulting in a frameshift that produced a premature termination at codon 632. To date, five missense mutations have been identified;

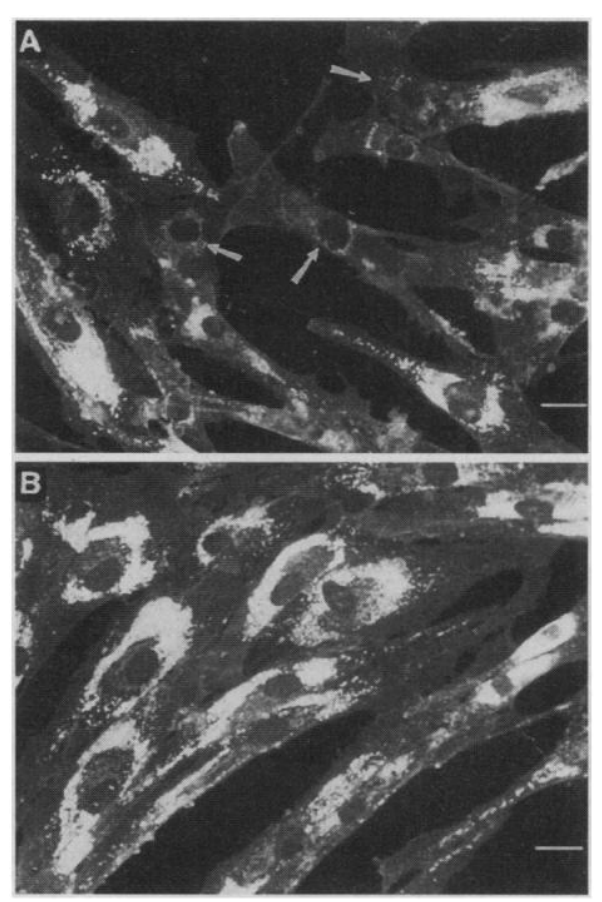

Fig. 3. Cytochemical detection of intracellular LDL-derived cholesterol accumulation in NP-C fibroblast cultures transiently transfected with NPC1 cDNA. Transfected NP-C cells were cultured with LDL (23). Cells were stained with filipin a specific cytochemical marker of unesterified cholesterol (3), and viewed by fluorescence $\mathrm{mi}$ croscopy. Cells transfected with sense 5-4 cDNA (A) show corrected cells (arrows) which contain fewer filipin-fluorescent lysosomes. After transfection with antisense 7-5 cDNA (B), essentially all cells contain intensely filipin-fluorescent lysosomes characteristic of the NP-C phenotype. Bar $34 \mu \mathrm{m}$. 
in two instances identical mutations, Thr to Met at codon $1036(\mathrm{C} \rightarrow \mathrm{T}$ transition $)$ or Asn to Ser at codon $1156(\mathrm{~A} \rightarrow \mathrm{G}$ transition), were found in unrelated families. Two of the missense mutations (Asn to Ser at codon 1156 and Arg to His at codon 1186 ) altered amino acids that are phylogenetically conserved. None of the mutations was observed in control DNA samples from 68 unaffected and unrelated individuals.

Introduction of NPC1 expression vectors into cultured NPC1-genotyped human fibroblasts by transient transfection restored a normal cellular phenotype as evaluated by filipin fluorescence (Fig. 3A) (23). In mock-transfected NP-C cultures, only $1.6 \pm 1.0 \%$ (Fig. $3 \mathrm{~B}$ ) cells did not show aberrant lysosomal cholesterol storage. By contrast, in NPC1-transfected cultures about $21 \pm 2 \%$ of the mutant cells showed no lysosomal cholesterol accumulation, indicating a significant $(P=$ 0.002) recovery of the normal phenotype. Thus, positional cloning, mutation detection, and cDNA-based functional correction establish NPC1 as the gene responsible for the major form of NP-C disease.

We have previously documented that NP-C cells show (i) excessive lysosomal accumulation of LDL-derived cholesterol, (ii) premature enrichment of cholesterol in trans-cisternal Golgi compartments, and (iii) delayed relocation of cholesterol to and from the plasma membrane (3). The presence of a putative lysosomal targeting motif suggests that NPC1 may move along an endocytic pathway that parallels the distribution of endocytosed cholesterol. The second NP-C genotype (NPC2 ) has an identical pattern of disrupted intracellular cholesterol transport (4), indicating that the sterol transport pathway or pathways may involve multiple proteins acting in tandem or in sequence. Cholesterol-mediated transcriptional regulation involves several proteins in the ER, including a sterol-sensitive protease activator (SCAP) (20), unidentified proteases (24), and proteasemobilized transcription factors (25). When released from the ER, these proteins move to the nucleus to regulate transcription of genes that control the levels of cellular cholesterol and fatty acids. Conceivably, NPC1 has a SCAP-like role, perhaps involving interactions with other proteins such as NPC2. Alternatively, as suggested by its homology with PATCHED, NPC1 may be a receptor for proteins involved in cholesterol transport.

\section{REFERENCES AND NOTES}

1. M. S. Brown and J. L. Goldstein, Science 232, 34 (1986).

2. J. L. Goldstein, S. E. Dana, J. R. Faust, A. L. Beaudet, M. S. Brown, J. Biol. Chem. 250, 8487 (1975).

3. P. G. Pentchev, M. T. Vanier, K. Suzuki, M. C. Patterson, in Metabolic and Molecular Bases of Inherited Disease, C. R. Scriver, A. L. Beaudet, W. S. Sly, D. D. Valle, Eds. (McGraw-Hill, New York, 1995), pp. 2625-2639.

4. M. T. Vanier et al., Am. J. Hum. Genet. 58, 118 (1996).

5. P. G. Pentchev et al., FASEB J. 1, 40 (1987); L. Liscum and J. Faust, J. Biol. Chem. 262, 17002 (1987).

6. E. D. Carstea et al., Proc. Natl . Acad. Sci. U.S.A. 90, 2002 (1993).

7. E. D. Carstea et al., unpublished data.

8. Patient DNA samples consist of a pan-ethnic selection from more than 40 NPC1 families whose genotype (4) and phenotype (3) were established. All patient and control DNA samples were obtained under the guidelines approved by clinical and research committees of the National Institutes of Health.

9. J. Z. Gu et al., Proc. Natl. Acad. Sci. U.S.A., in press.

10. BAC DNA was subcloned into exon-trapping vectors pSPL3 and pTAG4 as described [D. B. Krizman et al., Method's Mol. Biol. 68; 167 (1997)].

11. G. D. Schuler et al., Science 274, 540 (1996).

12. Long-range polymerase chain reaction (PCR) was performed on a human fetal brain Marathon-Ready CDNA library with Advantage Klentaq Polymerase Mix (Clontech). An antisense primer, 5'-TATTCTGCACAGACACTGCATCGTG-3', was designed on the basis of the $5^{\prime}$ sequence of EST clone $\mathrm{H} 11600$ (GenBank), and its reverse primer was provided by the manufacturer. Amplification products were subcloned into TA-vector (Invitrogen) and sequenced. For further $5^{\prime}$ extension from human MarathonReady cDNA libraries, additional antisense primers (5'-CGCTTGTTCCATCTTCAGCACCTCTGACAC$3^{\prime}, \quad 5^{\prime}$-CAGAAAGTGCGTGTGGTAATCGGCATACAC-3', 5'-GTGCAGTTCGTGTTATACGGTGAAAGAGGG-3') were designed from newly identified NPC1 sequence. Full-length NPC1 was generated by PCR amplification of human fibroblast and human ovary Marathon-Ready cDNA libraries, performed with $5^{\prime}$ untranslated region (UTR) primer $704 \mathrm{~F}\left(5^{\prime}\right.$ TGCTCCTGCTCCTCCGCTC-3') or 87F (5'-AACCAGCCGAACGCCGCC- $3^{\prime}$ ) paired with the $3^{\prime}$ UTR primer G-60 (5'-GTCCCTCATTTCATGCCACATC$3^{\prime}$. PCR products were cloned into expression vector pCR3.1 (Invitrogen). Orientation was determined by digestion with Sac I.

13. Molecular mass determinations were made with the GCG program PEPTIDESORT [J. Deveraux, P. Haeberil, O. Smithies, Nucleic Acids Res. 12, 387 (1984)]. PSORT [D. J. McGeogh, Virus Res. 3, 27.1 (1985), modified by K. Nakai and M.,Kanehisa [Proteins Struct. Funct. Genet. 11, 95 (1991)\} was used to detect signal peptide sequence. The same sequence was predicted by GCG-MOTIFS. TM domains were predicted with TMbase [K. Hofmann and W. Stoffel, Biol. Chem. Hoppe-Seyler 374, 166 (1993)] and the method described by P. Klein, M. Kanehisha, and C. DeLisi [Biochim. Biophys. Acta 815, 468 (1985)]

14. S. Ortgata and M. Fukuda, J. Biol. Chem. 269, 5210 (1994); I. V. Sandoval et al., ibid., p. 6622

15. W. Hunziker and C. Fumey, EMBO J. 13, 2963 (1994); F. Letourneur and R. D. Klausner, Cell 69, 1143 (1992)

16. S. K. Loftus et al., Science 277, 232 (1997).

17. W. H. Landschultz, P. F. Johnson, S. L. McKnight, ibid. 243, 1681 (1988).

18. J. A. Cooper, F. S. Esch, S. S. Taylor, T. Hunter, J. Biol. Chem. 259, 7835 (1984).

19. R. L. Johnson et al., Science 272, 1668 (1996).

20. X. Hua, A. Nohturff, J. L. Goldstein, M. S. Brown,
Cell 87, 415 (1996).

21. D. J. Chin et al., Nature 308, 613 (1984).

22. SSCP analysis was carried out on both cDNA and genomic DNA samples. cDNA was generated from cultured fibroblast RNA with Superscript II RNase $\mathrm{H}$ Reverse Transcriptase (Gibco-BRL). For genomic DNA, intron-exon boundaries were identified for 19 exons of NPC 1 (constituting $72 \%$ of the ORF), thus permitting PCR-based SSCP analysis from genomic DNA with primers designed from intron sequences. DNA was isolated from blood with the Puregene kit (GentraSystem, Minneapolis, MN). PCR was performed in $10-\mu$ l reactions containing $0.5 \mathrm{U}$ of Taq (Perkin-Elmer), $50 \mathrm{ng}$ of DNA, and $0.25 \mathrm{mM}$ each of dATP, dGTP, dTTP, and [32P]dCTP. Samples were subjected to electrophoresis on $0.6 \times$ tris-borate EDTA-buffered Mutation Detection Enhancement (MDE) (FMC Products, Rockland, ME) SSCP at $4 \mathrm{~W}$ for 14 hours. SSCP conformers were excised from the gel and reamplified by means of the original primer set. Reamplification products were sequenced (Applied Biosystems, Foster City, CA) and compared to normal controls.

23. For transient transfection, DNA vectors 5-4 (704F/ G60), 8-1 (87F/G60), 1-1 (704F/G60), and antisense $7-5(704 \mathrm{~F} / \mathrm{G} 60)$ were extracted by alkaline Iysis and $\mathrm{CsCl}$ gradient centrifugation. On day 0 , NPC1 fibroblasts (GM-3123) were plated $(70,000$ cells per well) in Lab-Tek Chamber Slides (Nunc, Napeeville, IL). On day 1, lipofectamine transfection was done according to the manufacturer's recommendations (Gibco-BRL). On day 2, cells were rinsed once with phosphate-buffered saline, and Eagle's minimum essential medium containing $10 \%$ lipoprotein-deficient serum (LPDS) was then added to the cells for 36 hours and then replaced with LPDS medium with or without LDL $(50 \mu \mathrm{g} / \mathrm{ml})$ for 24 hours. The NPC1-genotyped cells were fixed, stained with filipin, and cytochemically viewed [E. J. Blanchette-Mackie et al., Proc. Natl. Acad. Sci. U.S.A. 85, 8022 (1988)]. For evaluation, 8 to 11 fields each consisting of $\sim 200$ cells, were randomly selected and viewed with a $25 \times$ objective. Intense filipin fluorescence staining of cholesterol in perinuclear vacuoles was used as a marker of the lysosomal cholesterol accumulation characteristic of NP-C cells. Individual cells free of this intense fluorescence were scored as "corrected." Frequently, the corrected cells appeared in patches of two or more cells, and their lysosomes were often seen scattered throughout the cytoplasm. In untransfected, vector-only transfected, and antisense NPC1 transfected cultures, 1.9, 0.4, and $2.4 \%$, respectively, of the mutant NPC1 cells showed no filipin staining of perinuclear vesicles. By contrast, in cultures transfected with the NPC1 vectors $5-4,8-1$, and $1-1,23,22$, and $19 \%$, respectively, of the mutant cells showed no filipin staining.

24. X. Hua, J. Sakai, M. S. Brown, J. L. Goldstein, J. Biol. Chem. 271, 10379 (1996); J. Sakai, et al., Cell 85, 1037 (1996).

25. X. Wang, R. Sato, M. S. Brown, X. Hua, J. L. Goldstein, Cell 77, 52 (1994).

26. We thank D. Mosbrook and N. Dietrich for nucleotide sequencing, F. S. Collins for advice, E. A. Dawidowicz for many helpful discussions, D. Schoenberg for assistance in the preparation of the manuscript, and J. M. Trent for encouragement and mentoring. We thank the Ara Parseghian Medical Research Foundation and the National Niemann-Pick Disease Foundation for research support and the United Kingdom Niemann-Pick Foundation for helpful interactions. We foremost acknowledge the wisdom, courage, understanding, and faith of the Niemann-Pick $C$ patients and their families who have made this work possible.

8 May 1997; accepted 4 June 1997 